\title{
REVIEW
}

\section{Vitamin A and sleep regulation}

\author{
Hiroyoshi Sei \\ Department of Integrative Physiology, Institute of Health Biosciences, The University of Tokushima \\ Graduate School, Tokushima, Japan
}

\begin{abstract}
Vitamin A is the parent compound of retinoids, which regulate gene transcription by binding to nuclear retinoid receptors. Recently, it has been suggested that retinoid signaling pathways are important for adult neural function in health and disease. In this mini review we will summarize the molecular pathway of retinoid and experimental data on this pathway relating to sleep regulation, which suggests that retinoid signaling mechanism may be involved in the homeostatic component of sleep electroencephalogram. J. Med. Invest. 55 : 1-8, February, 2008
\end{abstract}

Keywords : vitamin A, retinoid receptor, sleep, delta oscillation, electroencephalogram

\section{VITAMIN A}

The beneficial effects of vitamin A might have been recognized by the ancient Egyptians, who treated eye disease with raw liver (1). They recognized a connection between eye problems and the liver, which is the richest source of dietary vitamin A. On the other hand, foods of vegetable origin do not have vitamin A, but provitamins for the formation of vitamin A do occur in abundance in many vegetable foods (2). These are yellow and red carotenoid pigments, which, because they have chemical structures similar to that of vitamin A, can be changed into vitamin A during intestinal absorption.

The well-known basic function of vitamin $A$ is the formation of the retinal pigments of the eye. However, today, we know that vitamin A (retinol) and its biologically active derivatives, the retinoids (the most potent of which is all-trans-retinoic acid (RA)), regulate key processes such as inhibition of cell proliferation, differentiation, apoptosis, shaping of the embryo, and organogenesis (3). Vitamin A deficiency

Received for publication December 10, 2007 ; accepted January 9, 2008.

Address correspondence and reprint requests to Hiroyoshi Sei, Department of Integrative Physiology, Institute of Health Biosciences, The University of Tokushima Graduate School, Kuramoto-cho, Tokushima 770-8503, Japan and Fax : +81-88-6339251. causes congenital malformations of the eye, heart, gonads, and lungs. In both youths and adults, lack of vitamin A impairs growth, vision, reproduction, and homeostasis of several organs. Active metabolites of vitamin A can prevent and cure a majority of these defects. In addition, retinoids have anti-cancer properties, as illustrated by their efficacy in the treatment of promyelocytic leukemia (3).

The wide spread nature of the bioactivities of retinoids is due, in large part, to the ability of retinoids to regulate the expression of target genes. It is now well established that retinoids regulates genes which control neural differentiation, neurite outgrowth, and the patterning of the anteroposterior axis of the neural tube $(4,5)$. And more recently, evidence has emerged that retinoid signaling may also be required for neural aspects of adults brain function (6).

\section{RETINOID RECEPTORS}

The actions of vitamin A's metabolites are primarily mediated by nuclear retinoid receptor proteins termed retinoic acid receptors (RAR-alpha, -beta, and -gamma) and retinoid " $\mathrm{X}$ " receptors (RXRalpha, -beta, and -gamma). These receptors are members of the steroid receptor family and essentially 
they function as transcription factors. The RAR and RXR exist and work forming heterodimers with each other, or with other nuclear receptors such as thyroid hormone receptors, vitamin D receptors, and the peroxisome proliferation activated receptor. The RAR and RXR, as with all nuclear receptors, contain a DNA-binding and ligand-binding domains. The ligand specificities of these receptors differ. RAR bind RA with high affinity and 9-cis-RA with lower affinity, whereas RXR bind 9-cis-RA (7). The effects of Vitamin A and its derivatives on gene transcription are presumed to be mediated largely by RA interactions with RAR since 9-cis-RA is undetectable in any tissues in vivo (8). Activation of the RAR-RXR heterodimer is controlled by RAR because RXRselective ligands do not induce gene transcription, a phenomenon termed "RAR dominance" (9). However, once an RAR ligand is bound, RXR ligands can increase the transcriptional efficiency of the RARRXR heterodimer (10).

The distinct temporal and spatial expression pattern of each retinoid receptor subtype and isoform suggests that they each may regulate specific neuronal phenomena. Only two of the RAR, RARalpha and RARbeta, are detected at high levels in the adult brain with RARgamma expression being very low. RARalpha protein has a fairly widespread distribution with particularly high levels in the hippocampus and cortex (11). On the other hand, RARbeta and RXRgamma have a more restricted distribution including dopamine-innervated areas such as the caudate/putamen and nucleus accumbens (11). The distribution of the RAR indicates the potential for several areas of the adult brain to respond to retinoids. Indeed, studies performed in the mice having RAR and RXR double mutantation demonstrate that this is the case. Impaired long-term potentiation and long-term depression, cellular mechanisms underlying memory and learning, have been demonstrated in mice lacking for RARbeta alone, or both RARbeta and gamma (12). On the other hand, in RARbeta-RXRbeta or RARbeta-RXRgamma double null mutant mice, reduced forward locomotion and rearing frequency was observed in the open field test (13). Mutants involving either RARalpha or RARgamma alone, or RARalpha-RXRgamma combination did not show any defects in locomotor tests, suggesting a specifity of the retinoid signaling pathways, with respect to RARbeta, RXRbeta and RXRgamma, is involved in regulating movement. In addition to the locomotor deficit, the expression of the dopamine D1 and D2 receptors was decreased $40 \%$ in the striatum of RARbeta-RXRbeta and RARbeta-RXRgamma null mice, but not in RARbeta or RXRgamma single mutants (13).

\section{SLEEP REGULATION}

Humans spend approximately one third of their lives to sleeping, but the purpose of this ubiquitous behavior remains to be clarified. The overpowering nature of sleep and the fact that restful awake periods do not satisfy the need for sleep has led to the suggestion that the purpose of sleep involves maintenance and repair of central neurons (14). For this maintenance and repair to occur, it appears that a difference in brain activity is required, that is, the slow, delta oscillation $(<2 \mathrm{~Hz}$ in human, $<4 \mathrm{~Hz}$ in mice) in electroencephalogram (EEG) observed during deep sleep.

Slow wave sleep (SWS) is known to be a deep sleep defined by EEG delta oscillation. SWS is also referred to as non rapid eye movement (NREM) sleep (stage 3 and 4). The power of the delta oscillation is a reliable parameter for an assessment of sleep depth and homeostatic need for sleep (15). The delta power depends on prior waking (16). It is well-known that sleep deprivation (SD), that is, forced wakefulness, causes a large increase in the delta power. This homeostatic mechanism of sleep is thought to have an essential role for rest and maintenance of neural function. Tononi and Cirelli have suggested that the homeostatic regulation of the delta power in sleep is linked with synaptic potentiation and rescaling $(17,18)$. It is hypothesized that the increased density of synapse during wakefulness is arranged and downscaled during SWS. Furthermore, Huber, et al. have demonstrated that a local increase in the delta oscillation in sleep after a motor learning task correlates with improved performance in humans (19). However, the neural and/or molecular mechanisms in generation of the delta oscillation remain unclear.

\section{RETINOIC ACID RECEPTOR AND SLEEP REGULATION}

We performed SD experiment with mice in order to see the change of gene expression in the brain relating with sleep loss using cDNA microarray (unpublished data). We found only one gene which was significantly increased, that is transthyretin (Fig. 1). 
Transthyretin has a critical role as a transporter protein for retinol. On the other hand, Maret, et al. recently reported that the gene encoding the RAR determines the contribution of the delta oscillation in the sleep EEG in mice (20). Changes in the relative contribution of delta oscillations to the SWS EEG are linked to RARbeta gene and more specifically to RARbeta1. These results raise the possibility that vitamin A (retinol and its derivatives) is involved in the regulation of the delta oscillation.

\section{normal sleep}

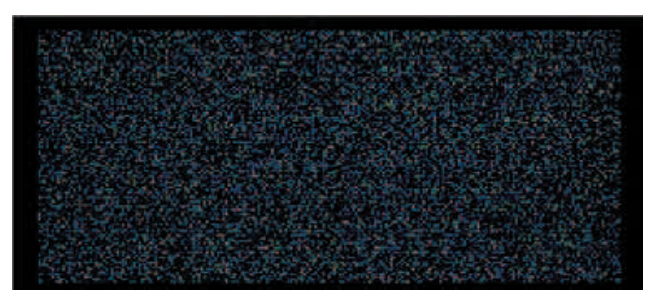

\section{6h sleep deprivation}

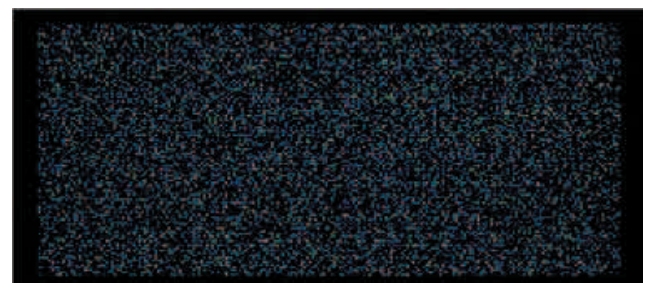

Fig. 1 cDNA microarray comparing genes expression between with and without 6 -h sleep deprivation.

\section{EXPERIMENT OF VITAMIN A DEFICIENCY} $(21,22)$

In order to clarify the linkage between vitamin A and the delta oscillation, we attempted to record the sleep EEG and behavior in mice fed a vitamin A-deficient (VAD) diet.

\section{Sleep scoring and delta power in NREM sleep}

Figure 2 shows representative EEGs and their power spectra during each stage (Wake, NREM and REM) in VAD and control mice respectively. The EEG consisted mainly of the delta frequency range in control mice during NREM sleep. On the other hand, in VAD mice, the EEG oscillation became faster and the delta power was lower than control mice (Fig. 2B). During both Wake and REM sleep, EEG patterns and power spectra were unlargely modified in VAD mice (Figs. 2A and 2C). The circadian profile of sleep/wake for $24 \mathrm{~h}$ was also affected unlargely by VAD (Fig. 3).

The hourly averaged power of the delta oscillation in NREM sleep differed significantly between VAD and control mice throughout $24 \mathrm{~h}$ (Fig. 4A). The averaged delta power for $24 \mathrm{~h}$ was significantly lower in $\mathrm{VAD}$ than in control mice (Fig. 4B). Figure 5 shows the recovery of the delta power in VAD mice for one week after the replacement of diet from VAD to normal. The feeding of the normal diet induced a significant recovery of EEG delta power in VAD.
A

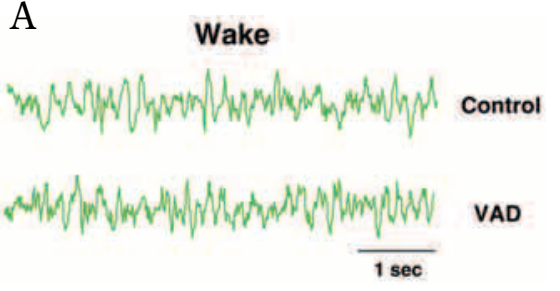

B
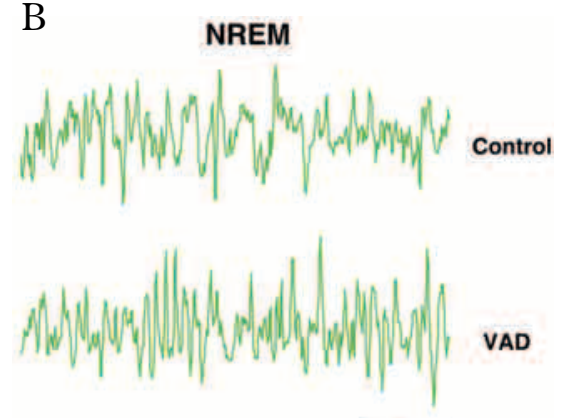

VAD
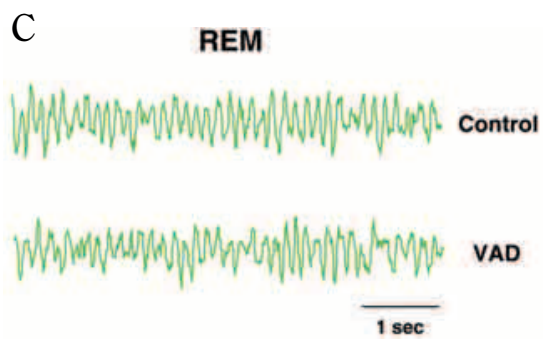

1 sec
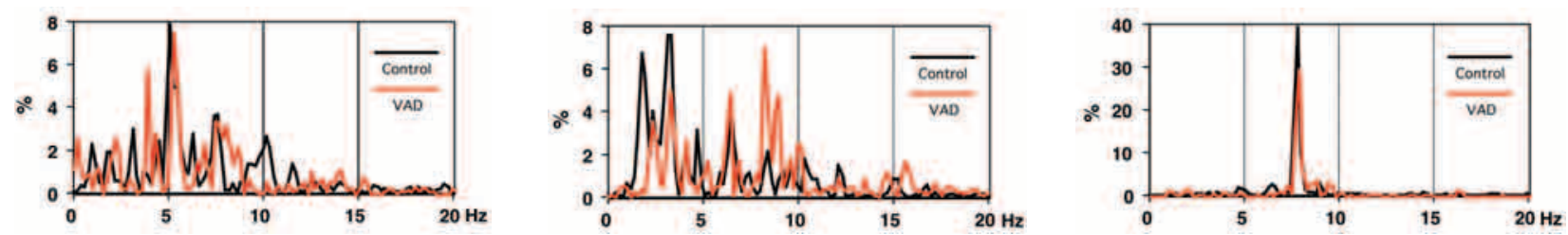

Fig. 2 Representative EEGs during Wake (A), NREM (B) and REM sleep (C) in four-week VAD and control mice and their power spectra (from ref.22). The EEG oscillation became faster in VAD mice compared with control mice in NREM sleep. Power spectrum showed the decrease of power in the delta frequency range $(<4 \mathrm{~Hz})$ in VAD mice. Note that the amplitude of EEG is almost the same. In Wake and REM sleep, EEG patterns and power spectra were quite similar between VAD and control mice. We defined NREM sleep in VAD mice by the increase of amplitude of EEG and the attenuation of EMG. 
A
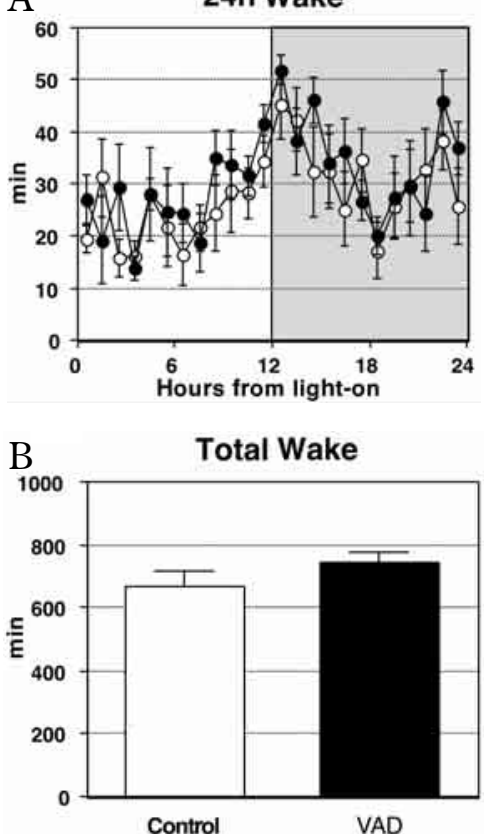
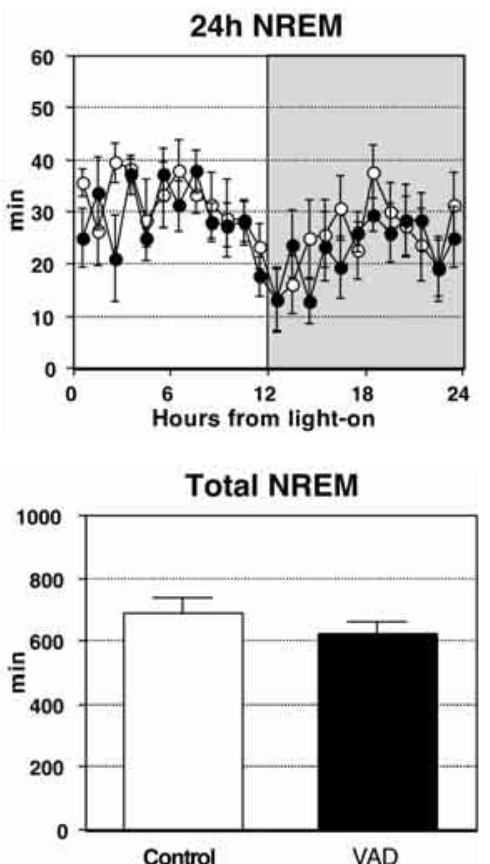

24h REM

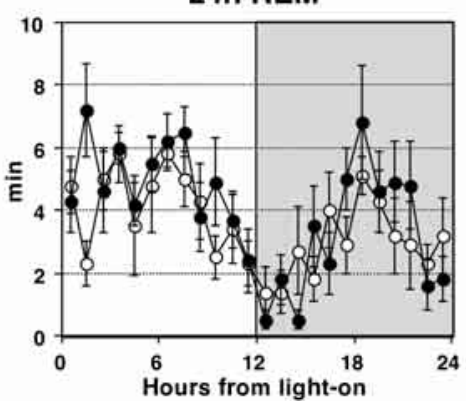

Total REM

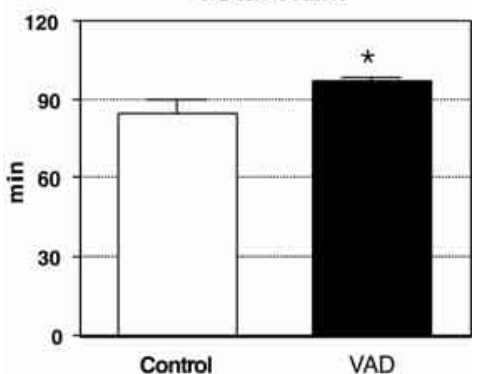

Fig. 3 Twenty-four hour time course changes in the amounts of Wake, NREM and REM sleep (A) and each total amount for $24 \mathrm{~h}$ (B) in VAD (filled circles and bars ; $n=6$ ) and control (open circles and bars ; $n=6$ ) mice (from ref.22). Each data point represents the mean \pm S.E.M. REM sleep was increased significantly in VAD mice. ${ }^{*} \mathrm{P}<0.05$.

A

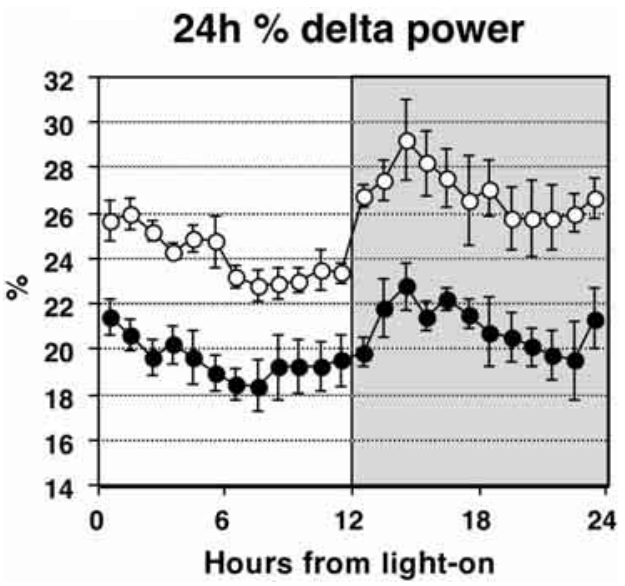

B

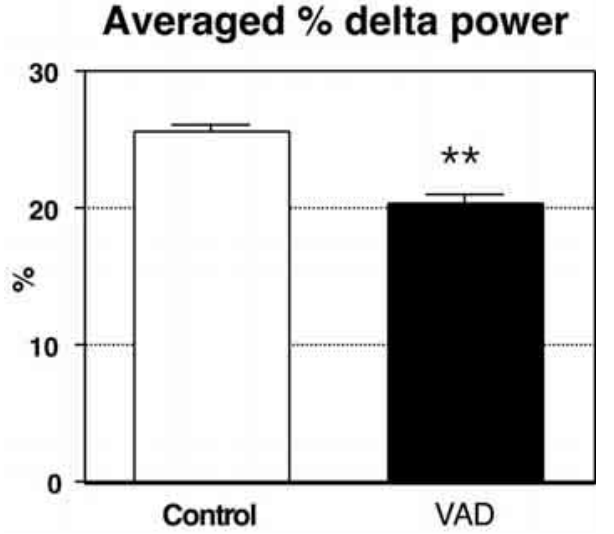

Fig. 4 Twenty-four hour time course change in the percentage (A) and averaged percentage of the delta power in NREM sleep (B) in VAD (filled circles and bars ; $n=6$ ) and control (open circles and bars ; $n=6$ ) mice (from ref.22). Each data point represents the mean \pm S.E.M. The delta power was decreased significantly in $\mathrm{VAD}$ mice compared with control mice. ${ }^{* *} \mathrm{P}<0.01$.
A

\section{Recovery of \% delta power}

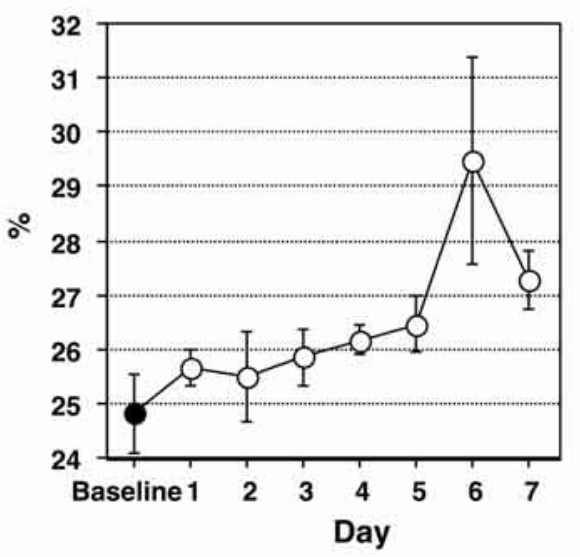

B

Averaged power spectrum

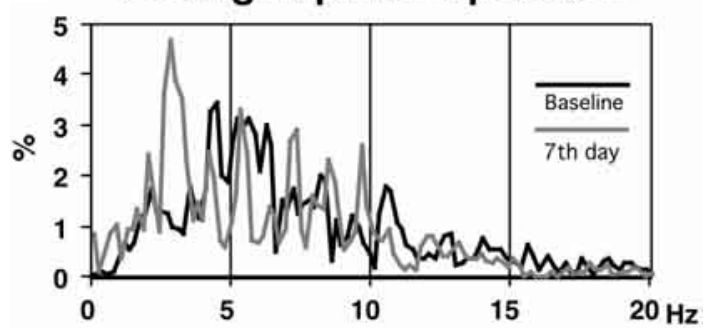

Fig. 5 The changes of percentage of delta power in VAD mice $(n=4)$ by the replacement of diet from VAD to control (A) (from ref.22). Just after baseline recording (filled circle), VAD diet was replaced with the control diet containing vitamin A (1.2 $\mu \mathrm{g}$ reti$\mathrm{nol} / \mathrm{g})$. Each data point represents the mean \pm S.E.M. Delta power was significantly recovered by 1-week control diet feeding. In the 7th day (gray line), the averaged power spectrum in NREM sleep recorded from $14: 00 \mathrm{~h}-15: 00 \mathrm{~h}$ showed the increase of delta power in comparison to that in the baseline day (black line) (B). 


\section{Spontaneous activity}

Circadian changes in spontaneous locomotor activity during $24 \mathrm{~h}$ differed significantly between $\mathrm{VAD}$ and control mice (Fig. 6A). Total spontaneous activity decreased significantly in VAD mice (Fig. 6B) compared with control mice.

A

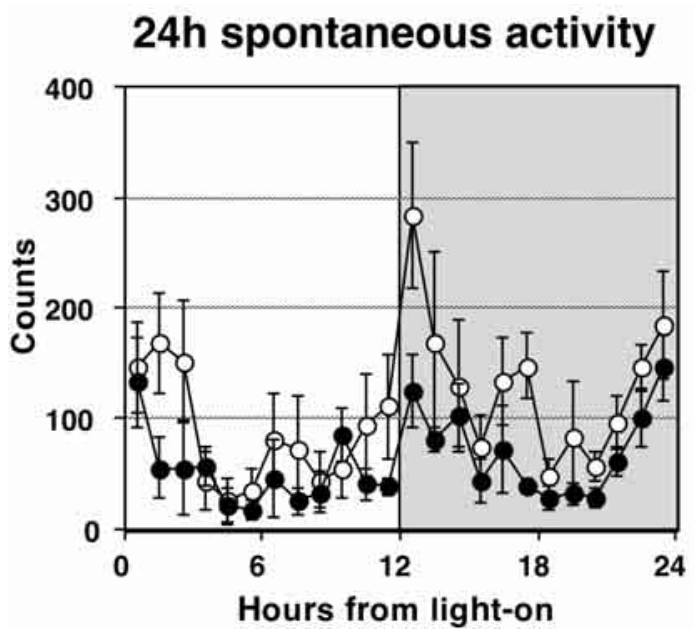

B

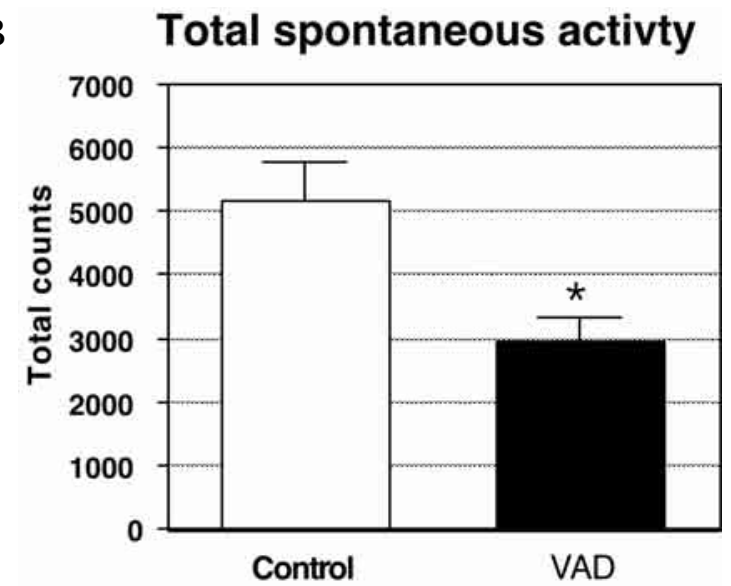

Fig. 6 The results of twenty-four hour recording of spontaneous locomotor activity (A) and total spontaneous activity over $24 \mathrm{~h}(\mathrm{~B})$ in VAD (filled circles and bar ; $\mathrm{n}=6$ ) and control (open circles and bar; $\mathrm{n}=6$ ) mice (from ref.22). Each data point represents the mean \pm S.E.M. The VAD mice showed a significant attenuation of spontaneous activity. ${ }^{\star} \mathrm{P}<0.05$.

\section{Sleep deprivation}

Figure 7 shows the effect of 6 -h SD on the delta power in $\mathrm{VAD}$ and control mice. Before $\mathrm{SD}$, the analysis of variance (ANOVA) showed a significant difference between VAD and control mice. After SD, the significance level became lower, and the averaged percentage of the delta power was no longer significantly different between VAD mice and control mice after SD.
A
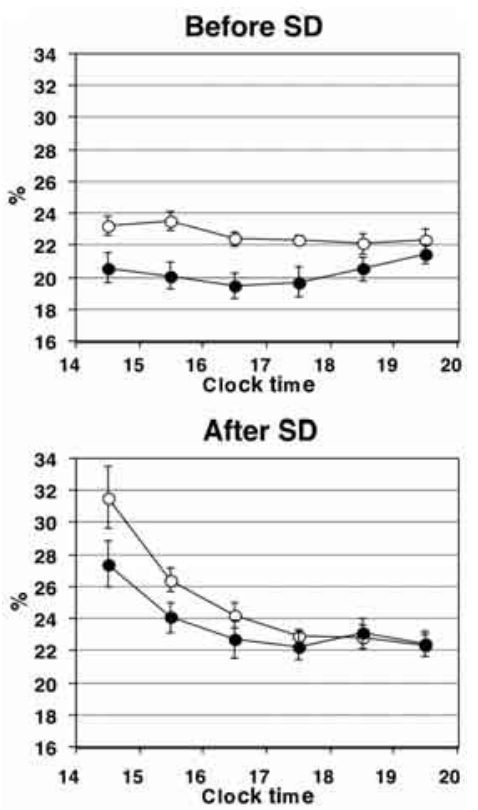

B
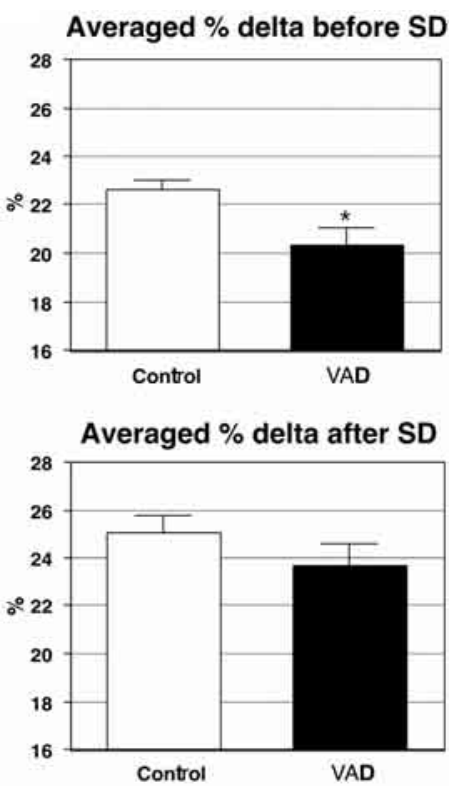

C Averaged power spectrum

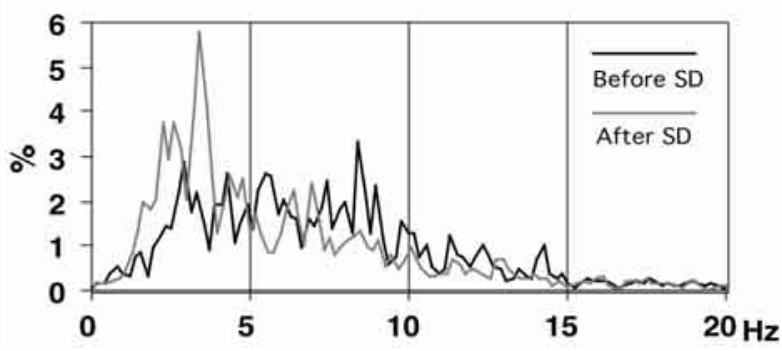

Fig. 7 Time course change of the percentage of delta power before and after sleep deprivation (SD) (A) and each averaged percentage of the delta power (B) (filled circles and bars ; $n=7$ ) and control (open circles and bars; $n=6$ ) mice (from ref.22). Each data point represents the mean \pm S.E.M. SD was started at the beginning of the light phase $(8: 00)$ and continued for $6 \mathrm{~h}$. Note that the difference of the delta power between VAD and control mice is diminished after SD. The averaged power spectra in NREM sleep recorded during the first hour after SD (gray line) and during the same clock time before SD (black line) also indicate the recovery of delta power by SD in VAD mice (C). ${ }^{\star} \mathrm{P}<0.05$. 


\section{Level of striatal monoamines}

We then quantified the striatal monoamines by high performance liquid chromatography to explore the effect of VAD on dopaminergic function. There was a significant difference between VAD and control mice in the dihydroxyphenylacetic acid (DOPAC) level (Fig. 8).
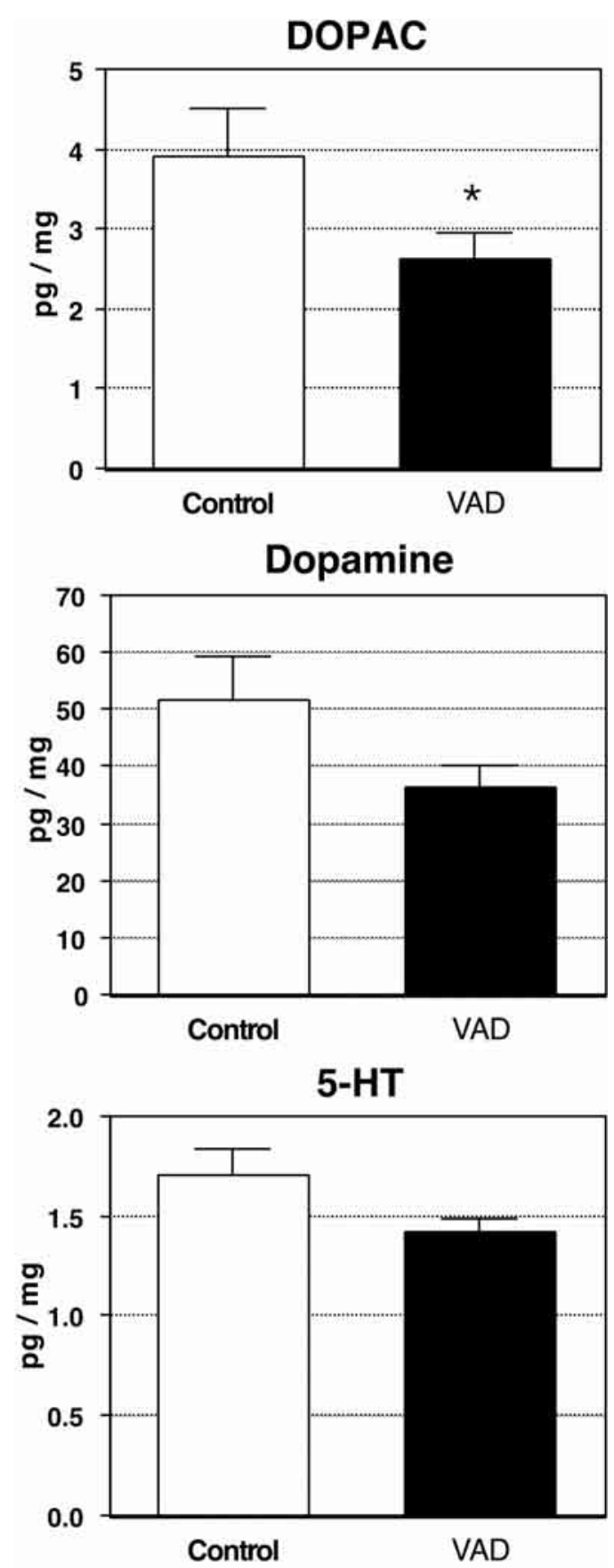

Fig. 8 The amount of striatal monoamines in VAD (filled bars ; $\mathrm{n}=8$ ) and control (open bars ; $\mathrm{n}=8$ ) mice (from ref.22). Each data point represents the mean \pm S.E.M. The amount of DOPAC in VAD mice was significantly lower than that in control mice. The differences between groups in dopamine and 5-HT did not reach the significant level. ${ }^{\star} \mathrm{P}<0.05$.
In the VAD experiments, we have found that VAD causes the attenuation in the delta oscillation, locomotor activity and striatal DOPAC levels. It is considered that diminished dopaminergic activity caused by VAD may induces the decrease of locomotor activity. We carried out a 6 -h SD to clarify the relationship between sleep homeostasis and VAD. Six-hour SD caused the recovery of the delta power in VAD mice to the level observed in the control mice. This result indicates that the mechanism for generation of the delta wave seems not to be impaired by $\mathrm{VAD}$, and prolonged waking periods can recover the delta wave even in VAD mice. It has been reported that significant deprivation of vitamin A and its metabolites is very difficult to induce in mice, because mice pups are born with sufficient vitamin A stores to last till their entire lives (4). In fact, although the level of plasma retinol was significantly decreased in our VAD mice, the difference was not so large. Furthermore, we have found that transthyretin, carrier protein for retinol, is increased by the SD (unpublished data). It is therefore possible that SD procedure may induce the additional outflow of vitamin A from the stock in the liver, resulting the recovery of delta oscillation. Although it still remains to be clear whether the effect of VAD is direct or indirect, vitamin A or its metabolites is considered to be involved in sleep homeostasis.

\section{PERSPECTIVE}

Today, we have several antagonists for RARs and RXRs. For example, LE540 is a RAR pan-antagonist (23), and HX531 is a RXR pan-antagonist (24). Using these antagonists, we should verify the role of RA on the sleep regulation.

Recently, we have found an interesting paper stating that decrease of transthyretin is one of the causes for impairment of memory function by ageing, because the supplement of retinoic acid, which does not need for help of transthyretin, improves the memory function (25). This finding raises the possibility that the impairment of sleep architecture by ageing, such as decrease of SWS and/or REM sleep duration, may also be induced by the decease of transthyretin. One of our ongoing studies is therefore on the effect of retinoic acid or agonists for retinoic acid receptors on sleep homeostasis in the model mice of ageing. 


\section{ACKNOWLEDGMENTS}

This work has been supported by JSPS under the Japan-U.S. Cooperative Science Program, and the Japanese 21st Century COE Program "Human Nutritional Science on Stress Control". Kazuyoshi Kitaoka and Sachiko Chikahisa (assistant professors of Tokushima Graduate School) have been contributing mainly to the works on retinoic acid.

\section{REFERENCES}

1. Michalik L, Wahli W : Guiding ligands to nuclear receptors. Cell $129: 649-51,2007$

2. Guyton A: In : Textbook of Medical Physiology. W.B. Saunders Company, Philadelphia, 1991, pp.782-783

3. Mark M, Ghyselinck NB, Chambon P : Function of retinoid nuclear receptors : lessons from genetic and pharmacological dissections of the retinoic acid signaling pathway during mouse embryogenesis. Ann rev pharmacol toxicol 46 : 451-80, 2006

4. McCaffery P, Zhang J, Crandall JE : Retinoic acid signaling and function in the adult hippocampus. J Neurobiol 66 : 780-91, 2006

5. Maden $\mathrm{M}$ : Retinoic acid in the development, regeneration and maintenance of the nervous system. Nat Rev Neurosci 8 : 755-65, 2007

6. Mey J, McCaffery P : Retinoic acid signaling in the nervous system of adult vertebrates. Neuroscientist $10: 409-21,2004$

7. Soprano DR, Qin P, Soprano KJ : Retinoic acid receptors and cancers. Annu Rev Nutr 24 : 20121, 2004

8. Mic FA, Molotkov A, Benbrook DM, Duester $\mathrm{G}$ : Retinoid activation of retinoic acid receptor but not retinoid $\mathrm{X}$ receptor is sufficient to rescue lethal defect in retinoic acid synthesis. Proc Natl Acad Sci USA 100 : 7135-40, 2003

9. Kurokawa R, DiRenzo J, Boehm M, Sugarman J, Gloss B, Rosenfeld MG, Heyman RA, Glass CK : Regulation of retinoid signalling by receptor polarity and allosteric control of ligand binding. Nature 371 : 528-31, 1994

10. Minucci S, Leid M, Toyama R, Saint-Jeannet JP, Peterson VJ, Horn V, Ishmael JE, Bhattacharyya N, Dey A, Dawid IB, Ozato K: Retinoid X receptor (RXR) within the RXR-retinoic acid receptor heterodimer binds its ligand and enhances retinoid-dependent gene expression.
Mol Cell Biol 17 : 644-55, 1997

11. Krezel W, Kastner P, Chambon P : Differential expression of retinoid receptors in the adult mouse central nervous system. Neuroscience 89 : 1291-300, 1999

12. Chiang MY, Misner D, Kempermann G, Schikorski T, Giguere V, Sucov HM, Gage FH, Stevens CF, Evans RM : An essential role for retinoid receptors RARbeta and RXRgamma in long-term potentiation and depression. Neuron $21: 1353-61,1998$

13. Krezel W, Ghyselinck N, Samad TA, Dupe V, Kastner P, Borrelli E, Chambon P : Impaired locomotion and dopamine signaling in retinoid receptor mutant mice. Science $279: 863-7,1998$

14. Ikeda M, Ikeda-Sagara M, Okada T, Clement P, Urade Y, Nagai T, Sugiyama T, Yoshioka T, Honda $\mathrm{K}$, Inoue $\mathrm{S}$ : Brain oxidation is an initial process in sleep induction. Neuroscience $130: 1029-40,2005$

15. Borbely AA : From slow waves to sleep homeostasis : new perspectives. Arch Ital Biol 139 : 53-61, 2001

16. Dijk DJ, Brunner DP, Beersma DG, Borbely AA : Electroencephalogram power density and slow wave sleep as a function of prior waking and circadian phase. Sleep 13 : 430-40, 1990

17. Tononi G, Cirelli C : Sleep and synaptic homeostasis : a hypothesis. Brain Res Bull 62 : 14350, 2003

18. Tononi $\mathrm{G}$, Cirelli $\mathrm{C}$ : Sleep function and synaptic homeostasis. Sleep Med Rev 10 : 49-62, 2006

19. Huber R, Ghilardi MF, Massimini M, Tononi G : Local sleep and learning. Nature 430 : 7881,2004

20. Maret S, Franken P, Dauvilliers Y, Ghyselinck NB, Chambon P, Tafti $M$ : Retinoic acid signaling affects cortical synchrony during sleep. Science $310: 111-3,2005$

21. Kitaoka K, Chikahisa S, Miyamoto K, Sei H : In Deficiency of vitamin A induces the decrease of slow-wave activity in mice, 2006 Neuroscience Meeting, Atlanta, 2006 ; Atlanta, 2006, p.361.4/ DD16

22. Kitaoka K, Hattori A, Chikahisa S, Miyamoto K, Nakaya Y, Sei H : Vitamin A deficiency induces a decrease in EEG delta power during sleep in mice. Brain Res $1150: 121-30,2007$

23. Umemiya H, Fukasawa H, Ebisawa M, Eyrolles L, Kawachi E, Eisenmann G, Gronemeyer H, Hashimoto Y, Shudo K, Kagechika H : Regulation of retinoidal actions by diazepinylbenzoic 
acids. Retinoid synergists which activate the RXR-RAR heterodimers. J Med Chem 40 : 4222-34, 1997

24. Kanayasu-Toyoda T, Fujino T, Oshizawa T, Suzuki T, Nishimaki-Mogami T, Sato Y, Sawada J, Inoue K, Shudo K, Ohno Y, Yamaguchi T: HX531, a retinoid $\mathrm{X}$ receptor antagonist, inhibited the 9-cis retinoic acid-induced binding with steroid receptor coactivator-1 as detected by surface plasmon resonance. J Steroid Biochem Mol Biol 94 : 303-9, 2005

25. Sousa JC, Marques F, Dias-Ferreira E, Cerqueira JJ, Sousa N, Palha JA : Transthyretin influences spatial reference memory. Neurobiol Learn Mem 88(3) : 381-5, 2007 